\title{
Proteome and Lipidome of Plant Cell Membranes during Development
}

\author{
M. F. Shishova ${ }^{a, *}$ and V. V. Yemelyanov ${ }^{b}$ \\ ${ }^{a}$ Department of Plant Physiology and Biochemistry, St. Petersburg State University, St. Petersburg, 199034 Russia \\ ${ }^{b}$ Department of Genetics and Biotechnology, St. Petersburg State University, St. Petersburg, 199034 Russia \\ *e-mail:mshishova@mail.ru
}

Received August 28, 2020; revised February 25, 2021; accepted February 28, 2021

\begin{abstract}
Intensive development of systemic biology involves intensification of such branches as proteomics and lipidomics, which are valid for systemic biology of plants. This trend is obvious due to the rapidly growing number of publications on proteomes and lipidomes of plant cells, tissues, and whole organs. Particulars of the plant nuclei, mitochondria, and chloroplasts have been rather well detailed in this regard. However, these data are scarce concerning the tonoplast, Golgi apparatus, endoplasmic reticulum, and other single-membrane organelles of the plant cell. This review surveys the current concepts related to specificity of protein and lipid spectra in the membrane structures of plant cells. The little data describing changes in these parameters in the course of development and under stress pressure are also analyzed.
\end{abstract}

Keywords: proteome, lipidome, mass-spectrometry, rafts, plasma membrane

DOI: $10.1134 /$ S1021443721050162

\section{INTRODUCTION}

The fundamental function of the eukaryotic cell membranes is compartmentalization of biochemical as well as physiological processes. Each compartment (organelle) creates unique conditions that are characterized by a particular $\mathrm{pH}$ level, specific spectra of macro- and microelements, bioactive compounds, diverse energy resources, and other features. This function is determined by the structure of biological membranes. According to the fluid-mosaic model put forward in 1972, the membrane is a lipid bilayer, which mainly constitutes of phospholipids and contains proteins submerged into the lipid matrix to a different extent $[1,2]$.

Numerous empirical data represent the diversity of the protein components of the various membrane structures. The list of these proteins includes transporters, receptors, enzymes, etc. They are involved in the signaling and metabolic functions and, in this way, fulfill adaptations of the plant cells to stress factors and bring the developmental programs into effect. For a long time, it has not been possible to characterize the

Abbreviations: GDG-glucuronosyldiacylglycerol; GGL-glyceroglycolipids; GPL_-glycerophospholipids; DAG_-diacylglycerol; DGDG-digalactosyldiacylglycerol; DPG-diphosphatydilglycerol; MGDG-monogalactosyldiacylglycerol; PMplasma membrane; SPL-sphingolipids; SQDG-sulfoquinovosyldiacylglycerol; PA-phosphatidic acid; PC-phosphatidylcholine; PE-phosphatidylethanolamine; PG-phosphatidylglycerol; PI-phosphatidylinositol; PS-phosphatidyl serine. protein spectra of different membranes and, all the more, to estimate the dynamics of a protein profile under the influence of different factors. These problems can be solved by up-to-date approaches of systemic biology, namely, proteomics, or, to be correct, the combination of genomics, transcriptomics, and proteomics.

The term proteome was advanced in 1995 to designate all the proteins of a particular biological object (cell, tissue, organism, etc.) that are genome-encoded and are synthesized under certain conditions [3]. The sequencing of the Arabidopsis thaliana genome, as well as those of many other plant species, was of revolutionary importance in identification of proteins and annotation of their functions. The proteomic analysis, based on such methods as two-dimensional polyacrylamide gel electrophoresis (2D-PAGE), high performance liquid chromatography, and mass spectrometry, makes possible identification and quantitative assay of proteins in a sample, revelation of their primary structure, and assessment of their posttranslational modifications $[4,5]$. The original comparison of different approaches to proteomic analysis is given in the work of Moshkovskii and Ptashnik [6]. The scale of only one modern proteomic investigation may deal with several hundreds and even thousands of proteins requiring identification and determination of their possible functions.

Rapid development of proteomics has brought about a good deal of facts underlying many databases. 
They represent primary protein sequences and their modifications (phosphorylation, glycation, etc.) along with a functional importance of various proteins, such as protein kinases, transcription factors, different enzymes, and proteins carrying out protein-protein interactions. Recently, Subba et al. [7] have described these databases in detail. We agree with the authors that the databases need further development. For example, it is necessary to create and develop the informational system encompassing the data on the proteomes of signal cascades, secondary metabolism networks, and various membrane organelles. Thus, Arabidopsis contains 27000 proteins and 25-30\% of them are supposedly integrated in the membrane $[8,9]$. Consequently, the comparative analysis of protein profiles of the plant cell membranes is of special interest.

Another rapidly developing discipline-plant lipidomics-is not less important. The term lipidome was originally put forward by analogy with the term proteome [10] and implies the overall array of lipids present in the particular cell, tissue, or organism. Like the majority of "omic" disciplines, lipidomics exploits high-technology and maximally automated methods of extraction, separation, and analysis of lipids together with bioinformatic processing of the results. Different kinds of liquid chromatography, followed by mass-spectrometry with different ionization techniques, are usually applied [11-14]. Most lipids are not high-molecular weight substances, being hydrophobic or amphiphilic, easily soluble in nonpolar solvents. They are products of carboanionic condensation of thioesters (fatty acid derivatives and polyketides) and/or those of carbocationic polymerization of isoprene (terpenoids including steroids) [11, 15]. Lipidome of the eukaryotic cell numbers from hundreds to thousands of individual lipids building the cell membranes and accumulating in the storage structures [14]. Despite a wide diversity of the current information, our knowledge of the changes in the lipid profiles in the course of development and in stress situations is still inadequate.

The present-day concepts on protein and lipid spectra of plant cell membranes will be considered below.

\section{DEVELOPMENT OF CONCEPTS CONCERNING DIVERSITY OF PROTEOME AND LIPIDOME OF MEMBRANE STRUCTURES OF THE PLANT CELL: HISTORY, PROBLEMS, AND PROSPECTS. PROTEOME OF CELLULAR MEMBRANES}

The first studies of proteomes of plant membranes were related to analyzing the proteins present in nuclei, chloroplasts, and mitochondria. These rather large double-membrane organelles were isolated by low-speed centrifugation. The subsequent identification of their membranes did not cast doubt.
The proteome of the Arabidopsis mitochondrial membranes is now one of the best-characterized. These data were reported as early as the work of Brugiere et al. [16]. Some time later, the application of different methods of extraction followed by LC-MS/MS analysis enabled identification of 114 proteins, which increased their number by $40 \%$. It was found that 80 functionally annotated mitochondrial proteins of Arabidopsis comprise the proteins involved in membrane transport (including that of electrons), di- and tricarbonic acid cycle, synthesis of amino acids and proteins, protection from oxidative stress, etc. [17]. Various up-to-date methods of proteomic analysis are capable of extending the protein profiles of these organelles up to $1000-1500$ proteins. In this regard, the investigation of various stable intramembrane protein complexes deserves special attention [18]. Indeed, this is valid for the complexes of respiratory electrontransport chain, the complex of alternative oxidase, the ATP-synthase complex, and the series of multicomponent transporters.

In the Arabidopsis chloroplast membranes, 242 proteins were initially revealed. At least $40 \%$ of them belong to the integral membrane proteins. The functions of the remaining 86 proteins were unidentified [19]. Further progress in methods made possible the detection of as many as 1200-1300 proteins in the chloroplast of this plant. They were found to participate in photosynthesis, sulfur and nitrogen metabolism, and synthesis of amino acids, fatty acids, hormones, secondary metabolites, pigments, vitamins, and other products. Locations of some of these proteins-in the stroma, thylakoid membrane, or lumen-were disclosed. In this regard, the large functional protein complexes in the chloroplast membranes are especially interesting [20]. They include the light-harvesting complexes, the protein complexes of photosystems, ATP-synthase, and multicomponent transport systems.

The study of nuclear proteome has also passed through a thorny way. In Arabidopsis, one of the first investigations revealed 200 nucleus-specific proteins [21]. The large-scale study identified as many as 663 proteins whose functional annotation was difficult to ascertain [22]. Among 345 nuclear proteins, the ones involved in the transcription and signaling systems, chaperones, and other proteins were reported. Similarly to chloroplasts and mitochondria, much attention has been currently paid to proteomic analysis of not only outer and inner nuclear membranes but also to identification of the transmembrane protein complexes of the nuclear envelope including its pores [23, 24].

Recognizing the evident success in the exploration of proteome of double membranes surrounding the corresponding organelles, one should mention that the investigation of different intracellular low-density membranes had initially been very difficult. Their isolation requires high-speed centrifugation. Separation 
of the plasma membrane, tonoplast, Golgi apparatus, and endoplasmic reticulum was originally carried out in density gradients of sucrose, sorbitol, Percoll, etc. [25]. However, such a procedure could not entirely prevent cross-contamination of the membrane fractions in most cases. This review does not aim at scrutinizing different methods. We can only state that the quite specific purification has been elaborated solely for the plasma membrane [26]. This two-phase separation has been successfully employed for more than 30 years. It is based on using of two immiscible solutions of polyethylene glycol and dextran; their concentrations are species- and tissue-specific. Some approaches were proposed for tonoplast isolation [27-29], although they are not generally accepted and require further improvement so far. After preparing a material containing a certain purified membrane fraction or that is enriched with it, a scientist faces several more important problems. They were summarized by Ephritikhine et al. [30]. The membrane-bound proteins, unlike soluble ones, are poorly separable by two-dimensional electrophoresis in polyacrylamide gel (2D-PAGE) because of their physicochemical heterogeneity and high hydrophobicity. Many hydrophobic proteins do not dissolve in a buffer intended for isoelectric focusing and precipitate at their isoelectric point. Besides, proteins are present at low concentrations in most membranes and often cannot be analyzed by standard proteomic methods. To cope with the mentioned obstacles, auxiliary extraction of hydrophobic proteins followed by mass-spectrometry are applied.

Because of a rapid development of analytical technique for membrane proteome, together with a reliable preparative method for plasma membrane (PM), it is this membrane that has been studied most intensively in terms of proteomics. Indeed, the significance of PM as a main barrier and essential participant of a cellular transport system also contributes to the interest in this membrane. In addition, the plasma membrane is involved in the perception of various chemical and physical external signals and their transduction into the cell, therefore, triggers a wide array of adaptive and physiological responses at a cellular level.

The first mass-spectrometrical analyses of the Arabidopsis plasma membrane revealed approximately 100 proteins; the most part of them had not been found in the earlier proteomic studies [31]. Nano-flow reversed-phase HPLC, coupled with tandem massspectrometry (nano-LC/MS/MS), revealed as many as 238 proteins in the plasma membrane fraction of the leaf cells of this plant [32]. More than 100 of them were attributed to ones containing one or more transmembrane domains. They are functionally related to the transport through PM, vesicular transport inside the cell, signal transduction, and responses to stressors. A small number of proteins was formerly associated with other cellular compartments and might originate from contamination.
Investigations of recent years have considerably widened our knowledge of different protein groups of the Arabidopsis plasma membrane [33]. Because of a limited volume of the review, we shall confine ourselves to the main groups rather than all the annotated proteins. The proteins of PM are conventionally subdivided into three categories depending on a type of their association with the membrane: the integral membrane proteins, the peripheral membrane proteins, and the glycosylphosphatidylinositol-anchored proteins. The members of the first group possess one or more transmembrane domains. At the N-end, the signaling sequence, fulfilling the delivery of proteins into the plasma membrane through ER and Golgi apparatus, is situated. The systems of passive and active ion transport primarily belong to this group. The most numerous representatives are $\mathrm{H}^{+}$-ATPase, aquaporin [34], various transporters of ions (including heavy metal ions), the transporters of organic molecules (including hormones), and the proteins performing signaling functions (e.g., receptor-like kinases, RLK). The peripheral membrane proteins do not have a sufficient hydrophobic domain. They are bound to the plasma membrane through noncovalent protein-protein interactions or the covalent lipid modifications resulting from $\mathrm{N}$-myristoylation, $\mathrm{S}$-palmitoylation, or prenylation. This group includes the proteins controlling vesicular traffic, including Rho of plants (ROPs) and Soluble N-ethylmaleimide sensitive factor Attachment protein REceptors (SNARE) proteins $[9,35]$. The proteins of the third group interact with the plasma membrane owing to glycosylphosphatidylinositol. This protein modification is supposed to occur in the Golgi apparatus. This group mainly consists of the enzymes involved in the cell wall construction, for example, $\beta$-1,3-glucanase, pectin esterase, and polygalacturonase [36]. The proteins present in the microdomains of the plasma membrane earn special attention. The microdomains (rafts, detergentresistant domains) are enriched with sphingolipids and sterols that create more ordered areas contrasting to the surrounding layer mainly composed of phospholipids [37]. The lipid components of the rafts will be considered hereafter. Now let us take a look at the protein components of these domains. Some proteins are markers of the rafts: KAT1 $\left(\mathrm{K}^{+}\right.$-channel), PIP2;1 (aquaporin), PIN1, PIN2, and some ABCB (auxin transporters), remorins (group of immune response proteins), etc. [38]. It should be noted that the rafts, despite their rather certain physicochemical properties, are dynamic structures with content depending on conditions and changing with time. Unfortunately, the ratio of the functionally different protein groups of the PM (transporters, enzymes, receptors, etc.) is rather difficult to figure out now since a large share of proteins has not been characterized so far.

Other single-membrane organelles are also the objects of proteomics. The first typical protein profiles of the vacuolar membrane (tonoplast) were obtained 
almost simultaneously with those of the plasma membrane, but the authors inferred that the membrane preparations were excessively contaminated. The situation was much improved in the case of the suspension-cultured cells of Arabidopsis and their protoplasts [39]. In total, 263 proteins were revealed. Each of 46 proteins supposedly possesses two transmembrane domains, and the remaining 177 have one such domain or none. According to the database, 129 proteins were annotated. This group includes $\mathrm{V}-\mathrm{H}^{+}$-ATPases, pyrophosphatases, and transporters of $\mathrm{Zn}^{2+}, \mathrm{Cd}^{2+}$, sucrose, and amino acids. The functions of 21 proteins are related to the system of protein degradation. In fact, 34 proteins still remain uncharacterized, and a few proteins were earlier annotated as components of different membranes. More complete characteristic of the tonoplast proteome of Arabidopsis was presented by Jaquinod et al. [40]. The analysis demonstrates that the identified proteins participate in the transportation of ions and metabolites (26\%), stress reactions $(9 \%)$, signal transduction (7\%), and metabolism (6\%); they also fulfill such vacuolar functions as hydrolysis of proteins and sugars.

The proteome of the Golgi apparatus was first reported in the 2000s [41]. However, the inability for correct isolation of the membranes from these organelles casts some doubt on the results obtained over that period. All the same, the interest in the Golgi apparatus is high, especially due to the intrinsic synthetic processes involved in the cell wall construction. Rather recently, a novel approach has been advanced, including purification in a density gradient followed by separation based on a surface charge [42]. This made it possible to achieve a sufficiently high degree of purification of the membrane fraction. The subsequent proteomic analysis has identified 491 proteins. Their list contains 64 proteins representing contaminations of different origin: from mitochondrial membranes (28 proteins), ER (15), and cytoplasm (14), together with six proteins that had formerly been identified as the components of plastids, nuclei, and peroxisomes. More than 50 proteins (namely, 56) were functionally ascribed to the protein synthesis system. The remaining 371 substances were qualified as participants of the polysaccharide biosynthesis of the cell wall matrix (20\%), transporters (12\%), transferases (12\%), and proteins responsible for secretion (12\%). A group of 55 proteins (12\%) represents different membranes, but they are not markers of the membrane contamination. For example, these are cellulose synthase and V-ATPase that are "transit" proteins of the Golgi apparatus.

Unfortunately, the cytoplasmic reticulum is very poorly studied in terms of proteomics. However, 182 proteins are ascribed to this organelle [41]. Thirty of them are still not characterized. The remaining proteins are involved in folding, modification of synthesized proteins, and in some other metabolic activities.
The first group includes two Sec63 homologs, five peptidase homologs; BiP, HSP90, calnexin, and calreticulin chaperones; nine protein disulfide isomerases, and peptidyl prolyl isomerase. The list of the identified compounds includes the proteins of the oligosaccharide transferase complex (ribophorin I homologs, ribophorin II, two STT3 homologs, OST3, OST6, OST48, and DAD1) that account for oligosaccharide transfer in the process of $\mathrm{N}$-linked glycosylation. The group of "metabolic" proteins comprise 18 cytochromes $\mathrm{P} 450$, NADPH-cytochrome P450 reductase, NADH-cytochrome b5 reductase, two proteins of cytochrome b5, and 11 proteins involved in lipid metabolism. The proteins of another group (including the $\mathrm{Ca}^{2+}$-ATPase family) maintain the ionic homeostasis in the ER, and several proteins (AtSEC12, COPII, RHD3 homolog, etc.) mediate an exchange between the ER and Golgi apparatus.

The development of sequencing techniques has extended proteomic analysis to other plant species, namely, cereals (rice, maize, oat, and rye) and dicotyledonous (tobacco, soybean, etc.). Different organs of these plants and cell cultures derived from them were examined [43]. In the oat and rye plasma membranes, not only protein profiles but also protein compositions of nanodomains were compared. With nano-LC-MS/MS analysis, 219 proteins were identified in oat and 213 in rye. Of them, 56 and $47 \%$, respectively, were the proteins specific for nanodomains. The authors succeeded in the detailed characterization of a ratio of different groups of functionally important proteins present in the plasma membrane or nanodomains in different cereal species [44].

Therefore, the mounting publications characterize protein spectra of membranes of the plant organisms that are of value for crop production and biotechnology. By the way, somewhat exotic plants are also reported as to their membrane protein profiles. For example, the plasma membrane and tonoplast from the leaves of mangrove Avicennia officinalis growing in equatorial marshes of Singapore were studied. Here, even in the unsequenced genome, 254 proteins of the PM and 165 proteins of tonoplast were identified [45]. In field mint (Menta arvensis), fewer proteins (122) were found in the plasma membrane proteome, and only 21 of them were identified [46].

The interesting evidence of tissue specificity of the PM protein spectra was obtained on poplar plants [47]. Here, a relatively large part (42\%) of 956 proteins corresponds to the plasma membrane fraction of all examined tissues (leaf parenchyma, xylem, and cambium/phloem), and only $10-11 \%$ were unique of the particular tissue. By means of the further analysis, 213 integrated membrane proteins were qualified according to their functions related to "transporters," "receptors," "cell wall and carbohydrate metabolism," "transmembrane transport," "other," "unknown," and "possible contaminants." More than $70 \%$ of the 
transporters of the largest group of integral proteins are detected in the PM of the leaf cells, $32 \%$ are present in the membranes of all three tissues, and only $25 \%$ are exclusively found in the plasma membranes of the cells of xylem and/or cambium/phloem. It is surprising that the PM isolated from cambium/phloem contains the highest share of receptors. More than $70 \%$ of proteins participating in the cell wall formation and carbohydrate metabolism and all the proteins involved in membrane transfer are identified in the plasma membrane of xylem cells. Few proteins (2-4\% of the total number) were common for the PM of mesophyll and that of two other tissues. Meanwhile, the plasma membrane of xylem and cambium/phloem contains the proteins (21\%) that are not identified in such membranes of the leaf cells.

Another study performed on rice plants. It is a comparison of the proteomes of roots, etiolated and green leaves, growing leaf blades, and flowers [48]. In addition to 511 proteins common for the five organs, each organ possesses a set of specific proteins: root (270 proteins), etiolated leaf (132), green leaf (359), developing leaf (146), and flower (149). The protein profile of the root plasma membrane is found to considerably differ from that of leaves, regardless of the conditions (light or darkness) of their development. According to the PM protein composition, the developing lamina is closer to a flower than a green leaf. The fact that the root PM is richer in transporter proteins than the leaf PM, as well as the evidence that the flower PM is more saturated with signaling proteins than the plasma membrane of the green leaf, has aroused special interest.

Therefore, the results of the last decade, obtained with up-to-date methods, point to the specificity of the protein profiles either upon comparison between different tissues of one plant or between different plant species. This implies a functional significance of the protein components of the cell membranes. It is not questioned that the intense progress in sequencing, along with improvements in isolation techniques and analytical methods, will provide a basis for further investigations of proteomes of the membrane organelles.

\section{LIPIDOME OF PLANT MEMBRANES}

Membrane lipidomes are primarily constituted of polar lipids. Their amphiphilic nature allows their association to yield the bilayer membrane structure and fulfill plenty of different functions. These are polar lipids that provide a basis for the bilayer. The mass ratio of lipids to proteins is usually close to $1: 1$ in the plant cell membrane. However, the ratio would vary from $50: 1$ to $100: 1$ if we allow for the averaged molecular masses of lipids and proteins rather than their absolute content [49]. Most membrane lipids belong to glycerophospholipids (GPL), with a dominance of phosphatidic acid (PA), phosphatidylcholine (PC), phosphatidylethanolamine (PE), phosphatidyl serine (PS), phosphatidylinositol (PI), diacylglycerol (DAG), and the corresponding lyso-forms. The less common components, especially of the inner cellular membranes, are phosphatidylglycerol (PG) and diphosphatidylglycerol (DPG, cardiolipin). The latter is a marker lipid of the inner mitochondrial membranes where it stabilizes the proteins of the electrontransport chain [50]. PC constitutes approximately $50 \%$ of the membrane phospholipids and, together with PE, this share is as much as 70-80\% [49]. The fatty acid composition of GPL encompasses C16-C24 acids, both saturated and unsaturated, where $\mathrm{C} 16$ and C18 dominate [51]. The trait of a plant lipidome is the almost absolute absence of plasmalogens-GPL, whose first position of glycerol is occupied, instead of the fatty acid residue, by the residue of alcohol with long aliphatic chain, which is linked with simple ether bound. Plasmalogens are widespread in animals, both invertebrate and vertebrate, including humans [14].

Another specific feature of plant lipidomes is the presence of galactolipids belonging to a special group of glyceroglycolipids (GGL). They build the membrane of plastids and are represented by monogalactosyldiacylglycerol (MGDG), digalactosyldiacylglycerol (DGDG), sulfolipid sulfoquinovosyldiacylglycerol (SQDG) [52], and glucuronosyldiacylglycerol (GDG) [53]. These lipids are found in higher plants, various eukaryotic algae, and oxyphotobacteria [14]. In the fatty acid composition of plant galactolipids, the $\mathrm{C} 16: 0, \mathrm{C} 16: 3$, and $\mathrm{C} 18: 3$ acids are the most abundant [54].

Sphingolipids (SPL) is an essential group of polar lipids. Their share may be as much as $10 \%$ of the total lipids in the plant [51]. For a long time, this group has remained inadequately explored because of difficulties of their extraction and analysis [11, 13, 55]. SPL are derivatives of long-chain aliphatic sphingoid bases (aminoalcohols). These bases are diverse among plant sphingolipids. In addition to sphingosine and sphinganine that are the most typical in animals, plants contain phytosphingosine and other derivatives. They differ from each other by the presence, quantity, and isomerism of double bonds as well as the number of hydroxy groups $[49,56]$. The fatty acid components that attach to a sphingoid base by an amide bond are represented by $\mathrm{C} 14-\mathrm{C} 26$ acids that are mainly longchain and are often hydroxylated at $\alpha$-position $[49,56]$. The saturated $\alpha$-hydroxy-C24 ( $\alpha$-hydroxy-lignoceric) acid predominates here [56]. In addition to sphingoid bases, plant SPL contains such key groups as ceramides, glucosylceramides (glycosphingolipids), and glycosylinositolphosphoceramides (phosphosphingolipids). These compounds average, respectively, $0.5,2$, 34 , and $64 \%$ of the total SPL amount in the leaves of Arabidopsis [51]. Sphingomyelin, as a chief sphingolipid of animals, is not present in plants.

One more essential group of the membrane lipids is represented by sterols-derivatives of isoprene. Con- 
siderable diversity of phytosterols-above 200 individual substances-is characteristic of plant membranes [57]. For instance, more than 60 individual sterols and pentacyclic triterpenes are isolated from maize seedlings [51]. In the lipidome of higher plants, the essential sterols are $\beta$-sitosterol, campesterol, and stigmasterol. The Arabidopsis cells accumulate up to 64, 11, and $6 \%$ of these compounds, respectively [57]. By the way, plants are also capable of synthesis of cholesterol up to $10-20 \%$ of the total sterol level, especially in the membranes of cereal root cells [57]. Phytosterols are usually present in the membranes in a free state. Nevertheless, they can be glycosylated by glucose, mannose, xylose, or galactose yielding steryl glycosides that, in turn, may be acylated by C16-C18 acids [49, $51,57]$. The esters of sterols with fatty acids can also be found in plants: rarely in membranes (as in cauliflower) but, rather, in lipid droplets together with triacylglycerides and other nonpolar lipids [49].

The lipid composition of the cell membranes depends on the cell type, age, developmental phase, and environmental factors. The particular species to which the plant belongs also matters, although considerable quantitative differences are even possible between individuals of one species [58]. The membrane lipidome of the PM and double-membrane organelles is the best-studied. The photosynthetic cells of plants contain 70-80\% membrane lipids in the chloroplasts, where $80-90 \%$ of polar lipids is concentrated in the inner mainly thylakoid membrane $[12,58]$.

The membranes of the plastid envelope do not contain chlorophyll and consist of glycerolipids (80\%) and free sterols (up to $1 \%$ ). The outer plastid membrane contains GPL (35-50\%), where PC (30-35\%, mainly in the outer monolayer) and PG (10\%) dominate. The share of GGL is $50-60 \%$ (DGDG is up to $30 \%$, MGDG is up to $17 \%$, and SQDG is $6 \%$ ). The inner membrane of the plastid envelope is primarily composed of GGL (85-90\%), where MGDG (50-55\%) in dominant. The GPL content does not exceed $15 \%$, and PG is a leader in this sense (up to $10 \%$ ) [52, 58]. The thylakoid membrane is chiefly formed of GGL as well. Its structure is asymmetrical: the outer monolayer is enriched with MGDG and PG, while the greater parts of DGDG and SQDG are localized in the inner layer, which faces the grana $[12,58]$. To be correct, we should note that MGDG is incapable of independently composing a bilayer. However, the role of MGDG is hard to be overestimated, because the ratio of MGDG to DGDG determines the bilayer formation, lipid-protein interaction, and interprotein interactions in the thylakoid membranes. The latter case is an energy interaction between the light-harvesting complex and PSII. Another function of MGDG is its interaction with the pigments of the xanthophyll cycle preventing photooxidation [59]. PE and PS are quite absent in the plastids [58]. Under conditions of phosphorous starvation, galactolipids of plastids can substitute for phospholipids in other cellular membranes and, thus, arise in the plasma membrane, tonoplast [51], ER, and mitochondrial membrane [54]. The chief substitute for GGL is DGDG whose share can attain one third of all the lipids under phosphate deficiency, while acylated sterylglycosides substitute for phospholipids in the outer layer [49, 60].

The lipids of the mitochondrial membranes consist of GPL by $80 \%$. The content of free sterols reaches $12 \%$ and that of their glycosides is $1-2 \%$ [58]. The chief GPL of the outer mitochondrial membrane are PC (up to 60\%), PE (25-30\%), and PI (15-25\%). The inner membrane also contains PC and PE (40\% each) and DPG (10-15\%) [58, 61]; DPG is specific to this membrane. Its share is zero in the tonoplast and does not exceed $2-3 \%$ in different intracellular membranes (the outer membranes of mitochondria and plastids, the peroxisomal membrane, and the microsomal fraction) [61, 62]. PS is also undetectable in the plant mitochondria [58,61]. Fatty acid residues with chain length C16:0, C18:2, and C18:3 prevail in GPL of the mitochondrial membranes [54]. Such peculiarity of lipid spectrum of these membranes may be due to the semi-autonomous lipid biosynthesis in the mitochondria. Actually, these organelles import GGL from plastids, DAG and GPL from ER, and synthesize PG and DPG by themselves [54, 63]. In addition, the mitochondria possess the proper system of fatty acid biosynthesis differing from that of plastids and starting from malonate [54].

Now, let us turn to the lipidome of single-membrane organelles. The ER membrane possesses the most diverse lipids participating in its formation. Of them, GPL are the most abundant (above $80 \%$ ), where PC (35-65\%), PE (10-25\%), and PI (3-18\%) prevail. Sterols in free $(3-14 \%)$ and bound forms $(1-4 \%$, including steryl glycosides and acetylsterylglycosides), together with sphingolipids (2-8\%, mainly glucosylceramides), are also present $[58,64]$. The peculiarity of the ER membrane is a relatively high level of PA $(0.5-7 \%)$ and lysophospholipids $(0.8-1.7 \%)$ because of the biosynthetic and transport roles of this organelle in arrangement of the cell lipid metabolism [64]. In addition, the ER contains up to $0.5-4 \%$ of the lipids typical of the membranes of plastids (MGDG and DGDG) and mitochondria (DPG) [58]. Such diversity is presumably accounted for by the ER role in lipid synthesis.

The present review does not pretend to comprehensively consider lipid biosynthesis. We only mention that fatty acids, including $\mathrm{C} 16-\mathrm{C} 18$, are synthesized in the plastids. Later on, they are transported to the ER membrane or participate in the prokaryotic pathway directly in the inner plastid membrane, where GGL and GPL are yielded [54]. The ER membrane is the chief place of lipid biosynthesis in the plant cell. The eukaryotic pathway of GPL synthesis proceeds here together with elongation of fatty acids, synthesis of triacylglycerides, sterols, sphingoid bases, cera- 
mides, and glucosylceramides [54, 56, 58]. Inositolphosphoceramides, glycosylinositolphosphoceramides, and complex sphingolipids with long oligosaccharide heads are synthesized in the Golgi apparatus [65].

Glyoxysomes are organelles specialized in lipid catabolism. Thus, their membranes contain not only GPL (25-50\%, especially PC, PE, PG, and PI) but also large amounts of free fatty acids (up to 30-40\%) [58]. It is thought that glyoxysomes themselves do not synthesize phospholipids but receive them from ER $[12,58]$.

Tonoplast (vacuolar membrane) consists of GPL (40-60\%), free sterols $(5-20 \%)$, bound sterols (10$25 \%)$, and glycosphingolipids (10-20\%) [27, 58, 62]. PC (30-50\%) and PE (24-50\%) dominate among GPL. The third GPL group is represented by PI (7$15 \%$ ), which are exclusively important for vacuole biogenesis [62]. The main components of tonoplast lipids are the $\mathrm{C} 16: 0, \mathrm{C} 18: 1$, and $\mathrm{C} 18: 2$ fatty acid residues [27]. The lipid-protein microdomains (rafts), rich in sphingolipids and sterols, are found in vacuolar membranes [27]. The V-type $\mathrm{H}^{+}$-ATPase is localized predominantly in these rafts [66]. As other inner membranes, the tonoplast contains plastid GGL (1-15\%) $[27,58,62]$.

The plasma membrane is also diverse in respect to the lipid composition. The peculiar feature of the plant PM is that it contains the maximal amounts of sphingolipids and sterols in comparison with the intracellular membranes. Another trait is a high variability in the ratio between GPL and other membrane lipids depending on the cell type, particular organ, or taxonomy $[49,57]$. The total pool of PM lipids is composed of GPL $(30-50 \%)$, SPL (5$40 \%)$, and sterols $(20-50 \%)[49,58]$. As in different membranes, the main constituents of GPL are PC (25-45\%) and PE (30-40\%). The remaining GPL are PS $(3-12 \%)$, PG $(2-15 \%)$, PI (2-11\%), and PA $(0-20 \%)[49,58,61]$. In comparison with other plant cell membranes, the plasma membrane, especially that of leeks, contains the maximal amount of PS. In addition, PM contains a minor fraction of PI derivatives (polyphosphoinositides or phosphatidylinositol phosphates) that are involved in signal transduction as precursors of inositol phosphates [51]. A small amount $(0-2 \%)$ of plastid GGL is appreciable in the plasma membrane [58]. In the shoot cells, the PM possesses GPL that are mainly acylated with C16:0, C18:2, and C18:3 acids; the residues of mono-, di-, and trienoic fatty acids with a long $(\mathrm{C} 20-\mathrm{C} 22)$ chain are also found $[49,54]$. In the root cells, phospholipids of PM contain mainly the residues of C16:0 and C18:2 acids [49]. In either roots or shoots, the content of saturated acyls equals or is half of that of unsaturated ones. It is interesting that PI, as majority of other GPL, is usually etherified with polyenic fatty acids (50-70\%), whereas the fatty-acid composition of polyphosphoinositides demonstrates higher saturation (10-20\%) [67].

Sphingolipids of plasma membrane are represented by glycosylinositolphosphoceramides $(25-30 \%$ of total lipids in this membrane) and glucosylceramides $(2-3 \%)$ [68]. Sterols are mainly present in a free form (70-80\% of total sterols) in the PM. In the leaf cells, conjugated sterols are primarily acylsterylglycosides $[49,68]$. It is sphingolipids and sterols of PM that are particularly involved in the formation of lipid-protein rafts. In these structures, their levels attain 70 and $20 \%$, respectively, while the part of glycerolipids was lower $10 \%$, while the fatty-acid component mainly consists of saturated radicals [68]. One molecule of sphingolipid interacts with three molecules of stigmasterol to yield a stable complex required for raft building [51].

One peculiarity of the plasma membrane arrangement is a different composition of inner and outer layers. The outer one is enriched with PC, SPL, and sterols, while PS, PI, (including polyphosphoinositides), and DGDG are situated only in the inner layer [60,68]. Such asymmetry is peculiar to both the plasmalemma and Golgi apparatus but not the ER. The origin of this disparity is unknown so far. Clearing this point up is hindered due to the high rate of the flip-flop movement of lipids in the membrane [69]. One trait of the cytoplasmic (inner) layer of PM is its negative charge [51]. In general, negatively charged phospholipids, primarily polyphosphoinositides, create an electric gradient, which can guide the processes of endocytosis. The electrostatic properties acquire a signaling function since they can determine the polarity of location of some proteins within the plasma membrane. Among these proteins is PINOID-the regulator of polar transport of the phytohormone auxin, proteinic components of the receptor of brassinosteroids, etc. The negative charge and $\mathrm{pH}$ gradient between the PM layers may also play a role in formation of the specially organized domains-rafts. They are also asymmetrically organized. The outer layer of a raft is enriched with sterols and glycosylinositolphosphoceramides with long heads bearing from three to seven glycosidic residues, while its inner layer contains more GPL, including the main amounts of polyphosphoinositides of PM [37, 68].

The interesting results were obtained in the studies of the plasma membrane lipidome in the area of plasmodesmata [70]. Here, the PM is enriched with sterols and sphingolipids with long-chain fatty acids; GPL of this membrane is acylated with fatty acid radicals that are less saturated than in the remaining PM. In this regard, the plasma membrane composition of the plasmodesma is similar to that of the lipid raft.

It was demonstrated that membrane lipids can exist in different phase states depending on the structure of the lipid and its ambient. Lipidomic studies of eukaryotic cells of animals show that lipid-lipid and lipidprotein interactions play considerable roles in deter- 
mining the functional activity of the membranes as well as the enzymes and transporters associated with them. Phase state of lipids can govern lateral heterogeneity of membrane layers. The lipid-lipid interaction between sphingolipids and sterols is a basis for an origin of rafts that were initially associated with cotransport of membrane proteins and sphingolipids from trans-domains of the Golgi apparatus to the plasma membrane [69]. The raft lipid composition is formed as early as the Golgi apparatus, where corresponding proteins incorporate into this lipid domain. Hydrophobic interactions between lipids and corresponding domains of proteins are regarded as a driving force of a self-organization of these domains. The recent investigations discovered the importance of the conformational rearrangements in transmembrane proteins (related to the structure of transmembrane domains, length and folding of cytoplasmic domains) for the subsequent organization of the raft and its delivery to the plasma membrane. Thus, the functional domains arise inside a phospholipid matrix. Different detergents are used to assess composition of rafts, thus, rafts are also called detergent-resistant domains. Raft size is also highly variable (in the range from micro- to nanometer) that was found with the help of high-definition microscopy [69]. It has been thought for a long time that it is lipids that play a role of a raft-forming component. However, according to recent data, the role of the protein constituents of the rafts is not so passive. For example, the thickness of the lipid layer may be defined by the length of the hydrophobic domain of the protein. Besides, multiplication of transmembrane protein domains increases affinity of sterols to this area of the phospholipid bilayer. Some proteins, for example, remorins (REM) are markers for rafts [71]. They are encoded by a multigene family consisting of six groups. These proteins are multifunctional. They are apparently involved in phytohormone interactions, development of nodules, suppression of pathogenic infections, formation of plasmodesmata, and other activities. In the scope of this review, one REM group is especially interesting. It contains the domain termed REM C-terminal Anchor (REM-CA). Its necessity for arrangement of the rafts (nanodomains of $100 \mathrm{~nm}$ in size) in the plasma membrane of the tobacco leaf cells was evidenced with the help of mutants in gene encoding this protein. REM-CA was demonstrated to support the protein association with the internal layer of the plasma membrane. The conformation of REM-CA undergoes changes in the presence of sterols and phosphatidylinositol-4-phosphate. It is suggested that the highly saturated acyl groups, present in the second compound (30-60\%), favor the preferential interaction with sterols and, therefore, behave as a driving force of nanodomain formation in the inner layer of the plasma membrane [71].

The represented facts witness to a wide diversity of lipid constituents of the membranes of the eukaryotic plant cells that is implemented by activities of the enzymes that are encoded by at least $5 \%$ of the genome [72].

\section{DYNAMICS OF PROTEOMIC AND LIPIDOMIC PROFILES}

The given evidence unequivocally shows wide spectra of protein and lipid composition of the plant cell membranes. It is generally accepted that this diversity determines the structure and, what is essential, the function of this cellular membrane. Some evidence shows that the membranes are very dynamic structures. In this respect, the changes in protein and lipid profiles of membrane organelles under stress impacts or in the course of development are of special interest. Here we will discuss the changes occurring in single-membrane organelles; the corresponding data are scarce and not systematized yet.

\section{CHANGES IN MEMBRANE PROTEOME UNDER STRESS AND DURING DEVELOPMENT}

The current investigations report the changes in protein profiles caused by such abiotic stress factors as excessive concentration of salts (including those of heavy metals), deprivation of water, and high or low temperature. The shifts in composition of membrane proteome are also revealed in the higher plants interacting with symbiotic or pathogenic microorganisms. In most cases, these studies were focused on analysis of the PM of the plant cells.

In rice plants subjected to salinization, 8 [73] or 18 [74] new proteins arise in the plasma membrane; these events are obviously stress-induced. The later investigation was carried out on the PM from oat roots [75]. Two cultivars, different in salt tolerance, were compared. In the protein profiles of plasma membrane, 479 proteins were identified. The presence of one or more transmembrane domains was predicted for 438 proteins. Supposedly, these proteins may fulfill such functions as primary and secondary metabolism, energy metabolism, transmembrane and vesicular transport, along with structural, protective, and signaling role. The subsequent analysis enabled ascertaining the considerable changes in the content of 182 proteins. Due to the characters of these changes, five clusters were isolated. The fifth one, containing 24 proteins, aroused the most interest. It manifested the maximal stress-induced accumulation in the salttolerant cultivar. Presumably, these proteins may fulfill metabolic, energy, storage, and transport functions. The greatest attention was paid to three proteins of this group responsible for binding of sterols or synthesis of phospholipids. The authors have proved the role of these proteins in regulation of the root development and increase in the tolerance upon salinization.

Some changes in the PM protein profile occur under low temperatures [76]. In Arabidopsis plants, 
38 proteins were revealed, including the proteins of Early Response to Dehydration (ERD10 and ERD14) and plant synaptotagmin 1 (SYT1), presumably affording membrane reparation after cold damage. Low temperature also modifies the microdomain composition of the plasma membrane. These changes affect P-type ATPases, aquaporins, tubulins, and proteins of clathrin-dependent endocytosis. The last evidence may point to active exchange in the PM composition.

The dynamic changes in the protein profiles of the PM of Arabidopsis leaves occur not only after a shortterm freezing (at $-2^{\circ} \mathrm{C}$ ) of the plants cold-acclimated for different times but also accompany their return to the normal temperature (deacclimation at $23^{\circ} \mathrm{C}$ ) [77]. The cooling leads to accumulation of 90 proteins and reduction in 200 in the plasma membrane. The last effect fits a general reduction in growing and metabolic activities of the chilled cells. Three functionally important groups of the stress-inducible proteins were qualified as transporters, metabolic proteins, and structure-maintaining proteins. The remaining ones were defined as the fourth unidentified group. The fact that the maximal changes in the protein profiles occur within different time intervals from the start of the acclimation indicates the complexity in the pathways of cold hardening. During deacclimation, the absolute majority of the dynamically changed proteins return to their original level.

Another harsh environmental challenge is submergence, which changes the ambient gas composition and, most crucially, diminishes the access of the root system to oxygen. In soybean seedlings, the proteomic analysis of subcellular membranes has revealed proteins that changed in number in response to oxygen deficiency [78]. Supposing the key role of the plasma membrane in plant adaptations to hypoxia, its participation in regulation of cytoplasmic $\mathrm{pH}$ and $\mathrm{Ca}^{2+}$ level, and its intimate connection with the processes in the cell wall, the mentioned investigation has disclosed the role of the changes in such proteins, as aquaporins, heat-shock proteins 70 , and several proteins of ionic homeostasis and signaling. The authors represented the changes in the tested 117 or 212 proteins (depending on the isolation technique) of the endoplasmic reticulum membranes. It was suggested that submergence primarily regulates the protein synthesis and glycosylation in ER of cells of soybean root. In any case, these data apparently require further analysis [78].

Not only abiotic but also biotic factors can alter the protein profile of the cellular membranes. For example, infection by the phytopathogenic fungus Alternaria alternata changes the content of 21 proteins in the PM proteome of mint (Mentha arvensis). They comprise functional groups: proteins participating in defense responses, those associated with carbohydrate and energy metabolism, and those accomplishing transport processes [46].
It appears that the most large-scale exploration of the dynamic changes in proteome associated with phytoimmunity was carried out on Arabidopsis plasma membrane [79]. In total, 2300 proteins were identified. Some proteins accumulate upon activation of the RPS2 receptor of plant-bacterial interaction. Of them, $20 \%$ included the PM proteins participating in calcium and lipid signaling, membrane transport, primary and secondary metabolism, vesicular transport, redox homeostasis, phosphorylation, etc.

Not the least shifts accompany the symbiotic interaction of barrel medick (Medicago truncatula) with the fungus of arbuscular mycorrhiza. The detailed comparison of the PM protein profiles of the root cells between mycorrhized and nonmycorrhized plants was recently carried out [80]. The dynamic changes in the content of 82 proteins were found in the course of mycorrhization. One third of these proteins are associated with the detergent-resistant microdomains of the plasma membrane. Some proteins are related to carbohydrate and lipid metabolism and are also involved in accomplishing metabolic exchange between the host-plant and symbiotic mycorrhizal fungus.

The symbiotic mutuality of legumes with nitrogenfixing bacteria is well known. The protein profiles of plasma membrane were analyzed in the model plant Lotus japonicus under these conditions [81]. In the peribacterioid membrane, 94 proteins were identified. They include a large group of transporters of sugars, peptides, sulfur, etc., aquaporins, several receptor-like kinases, and some proteins of protective responses. The results demonstrate the intensification of the metabolic and signaling processes during establishment of nitrogen-fixing symbiosis that is associated with the dynamic changes in the protein profiles of the peribacterioid membrane.

Let us consider now the available information on the proteome changes in the membranes in the course of development. Unfortunately, investigations are scarce in this field. The intrinsic step in the life cycle of the majority of plant cells is a unique process of an elongation growth. This may be regarded as a stage of differentiation of the cell, which undergoes manifold elongation. In the higher plants, the cell length usually ranges from 10 to $100 \mu \mathrm{m}$ on average but can attain even several centimeters in some cases. One classical model object to study elongation growth is the gramineous coleoptile. In this regard, the examination of microsomal and cytoplasmic proteomes of the rye coleoptiles [82] is of high interest. The coleoptiles were compared on day 3 of their development during their intense growth and on day 4 , when the coleoptile was breached with the true leaf, and its growth was dramatically (by 70\%) retarded. The proteins were separated by two-dimensional differential gel electrophoresis (2-D DIGE) followed by identification of the composition of the changing spots by reversed-phase liquid chromatography coupled with tandem massspectrometry (LC-MS/MS). The number of proteins 
in the microsomal fraction was found to sharply decrease upon the loss of growth capability. Since the corresponding database is absent for rye proteins, only eight dynamically changing proteins, including the E subunit of the vacuolar $\mathrm{H}^{+}$-ATPase, were identified.

Another conventional model organ to assess growth processes is a root. It contains several zones different in their functions and growth potential. The proteome of the cell wall $[83,84]$ and that of the microsomal fraction enriched with PM [85] were studied in the elongation zone of the primary roots of maize seedlings during their growth. Four root zones, including that of intense growth adjacent to the root meristem, were examined [85]. Before mass-spectrometric analysis, the proteins of the isolated fraction were separated by SDS-PAGE with the subsequent enzymatic cleavage to peptides in a gel. The changes in protein composition were quantitatively estimated by LC-MS/MS. As a result, the greater part (83\%) of the 574 analyzed proteins displayed no quantitative difference between the compared zones. The remaining proteins underwent nonlinear changes, including a total absence of a certain protein in some zones. Cellulose synthase and aquaporins represent the proteins whose content sequentially increased in the fractions from the root tip. The elongation zone was found to possess the maximal number (36) of unique proteins that were not found in other zones. Unfortunately, the absence of the sequenced genome of maize did not allow for identification of the proteins manifesting more complex dynamics.

In another unique study performed on the Arabidopsis suspension culture T87, the proteome of the plasma membrane was analyzed for the first time at different developmental stages of the cultured cells (lag, log, and stationary phases) [86]. The dynamics of protein profiles was also ascertained under a stress impact. The content of 392 proteins was found to change in the PM in the course of growth. They represent different functional groups indicating the changes in the PM physiological activity during passages through growth phases. Thus, two aquaporins (PIP2-1 and PIP2-5) accumulated upon a transfer from the logarithmic to the stationary phase. A similar dynamics was established for six PHT1-highly specific phosphate transporters of the plasma membrane. In the course of development of suspension culture, the changes in the levels of P-type $\mathrm{H}^{+}$-ATPase 1, 2, 3, 6, and 7 (but not VHA-A) were differently directed. The content of five ABC-transporters decreased and two increased over the log growth phase. The authors suggested that the discovered dynamic patterns in the content of these proteins are determined by the changes in activity of vesicular secretion (exocytosis and endocytosis), which is increased in the logarithmic but decreased during the stationary phase. The cited study also targeted the changes in the proteomic profiles caused by cold and/or ABA treatments. It was found that both factors afforded the effects with a strong dependence on the growth phase. The number of the chilling- and ABA-sensitive proteins decreased during the log growth phase. The results show that the regulatory processes are sophisticated not only in the whole cell but also at a level of the plasma membrane.

The rapid elongation of the cell may also occur due to apical growth, for example, in the case of a pollen tube. In the pollen of Easter lily Lilium longiflorum, the protein profiles were analyzed in the microsomal fraction, which was divided into five submembrane or organelle fractions, at the onset of the pollen germination and after the subsequent 10,30 , 60, and $240 \mathrm{~min}$ [87]. LC-MS/MS analysis revealed 270 proteins. At the earliest stages $(10-30 \mathrm{~min})$, the augmentation was observed for the proteins associated with cytoskeleton, carbohydrate metabolism, energy metabolism, and ionic transport. By contrast, the content of the proteins responsible for membrane or protein transport, signal transduction, and stress responses significantly decreased. At the same time, the levels of the proteins involved in the synthesis of amino acids, lipids or sterols, and the cell wall formation along with the transport of nutrients were independent of the pollen developmental phases. Therefore, the data have been obtained on the changes in proteomes of the PM and other endomembranes taking place during germination of the pollen grain and formation of the pollen tube.

The compelling evidence discloses the essential role of plasma membrane of the cells of germinating pollen in the intercellular interaction of the pollen with the pistil of rice plants [88]. The metabolic processes intensively proceed at the apical end of the pollen tube during its growth. The proteomic analysis has found 1121 proteins associated with the PM. Of them, the levels of 192 proteins changed, namely, increase for 119 and decrease for 73 proteins. These proteins belong to different functional groups, including signaling systems (primarily, receptor-like kinases) and transport systems engaged in the metabolic exchange between the pollen and pistil.

Another important process, which may be regarded as a developmental step, is fruit maturation. The marked changes in the protein composition were found in the microsomal fraction isolated from the pericarp cells of the of tomato fruits on days 30 and 45 from flowering. This corresponds to the completely formed (green) and ripe (red) fruits, respectively [89]. Nano-LC-MS/MS has revealed 1315 total proteins. The content of 145 significantly changed during maturation. With functional annotation, they were divided into several groups related to the cell wall metabolism, vesicular secretion, secondary metabolism, lipid and protein metabolism, signaling, and stress-induced responses.

With the help of 2D-electrophoresis and MALDITOF-MS spectrometry, it was found that the protein 
profiles of the plasma membrane significantly changed in the ripening grapes [90]. At the first stage of analysis of the purified PM fraction, 119 protein spots were identified. The subsequent analysis revealed 62 proteins presumably containing from one to six transmembrane domains. The identified proteins were ascribed to eight functional groups responsible for transport, metabolism, signaling, protein synthesis, etc. In the course of maturation, the number of proteins in the plasma membrane decreases from 119 through 98 to 86 proteins, respectively, on days 50,75 , and 95 from the flowering onset. The statistically significant decrease is detected for 12 proteins. They include Fe-binding protein, the precursor of apocytochrome $f$, putative xyloglucan endotransglucosylase, component of chaperone-protease complex, zeatin O-glycosyltransferase, ubiquitin-binding E2-21 enzyme, and other proteins yet unidentified. Their content in the plasma membrane decreased through different dynamics.

Upon fruit ripening, the essential role belongs to the vacuole, which can occupy as much as $90 \%$ of the cell volume. It is this organelle that determines the properties of fruits, since such metabolites as sugars, organic acids, and amino acids accumulate in it. The accumulation is managed by different transporters, enzymes, $\mathrm{pH}$-maintaining systems, etc. Quantitative proteomic analysis (iTRAQ), coupled with nano-LCMS/MS, made possible revealing 345 proteins in the tonoplast of ripening apples [91]. This group comprises different transporters of metabolites and ions (including the systems of primarily active transport), proteins responsible for signaling and metabolism, and proteins controlling vesicular secretion and adaptations to stressors. Moreover, the contents of 22 proteins changed in the course of the fruit storage. Therefore, the tonoplast proteome undergoes dynamic changes during not only development but also senescence of the fruits.

The given information infers that stress action on the plant organism, changes in the character of its growth, or passage to the next developmental phase are associated with the shifts in protein composition of the membranes, including plasmalemma, tonoplast, and those of ER and Golgi apparatus. Importantly, the dynamic changes of the membrane profiles can occur very rapidly, even in minutes. The changes may represent both increase in protein content (due to intensification of synthesis and/or vesicular secretion) and decrease (due to elimination of the proteins from the membrane composition through yet inadequately studied mechanisms). In this regard, the investigations, using highly purified membrane preparations isolated from the plants with a sequenced genome, are obviously necessary to be continued.

\section{CHANGES IN MEMBRANE LIPIDOME UNDER STRESS AND DURING DEVELOPMENT}

One more interesting aspect deals with the rapid changes in the membrane lipid composition in the plant cells. The technique of lipidomic analysis allows for highly distinguished detailing of these changes. In this respect, the consequences of certain stress factors are investigated. For example, these are increase in polyunsaturation of the fatty acid residues maintaining the membrane fluidity at low temperatures. Before the detailed consideration of these extreme situations, we are to look at normal processes of development. In the Arabidopsis leaves, the oscillations in the plasma membrane composition were reported [92]. This seems to be the first observation of rhythmic changes in the plant membrane lipidome. Under 12-h daily illumination, the composition of glycerolipids undergoes changes in the PC fraction. It was suggested that the lipid profile reflects a balance between the synthesis of new fatty acids and the process of reduction of acyl groups of fatty acids catalyzed by fatty acid desaturases (FADs). In this case, the C16 and C18 fatty acids, yielded in the chloroplasts, attach to glycerol due to acyltransferase activity that is followed by desaturation. As a matter of fact, acetyl-CoA carboxylase, unlike desaturases, is a light-dependent enzyme. It is suggested that the higher degree of saturation of the membrane lipids under light is accounted for by more intense de novo synthesis of fatty acids. In the darkness, desaturation prevails leading to rise in unsaturation. Summing up, we conclude that the membrane lipidome is a very dynamic structure, and its properties depend on plenty of factors. Continuing investigations are necessary to draw decisive conclusions on the factors that can control the oscillation changes in the membrane lipid profile.

The investigation of plant resistance to low temperatures has lasted more than 180 years [93]. It is inferred that this capability is controlled by a set of factors, and its establishment involves lots of metabolic pathways and genetic mechanisms. It was demonstrated many times that perception of a cold signal, its transduction, and formation of an adaptive response are closely related to lipids of the cellular membranes. Under this stressor, the membrane lipids convert from a liquid-crystal to a gel state that raises membrane permeability and electrolyte leakage. In this case, the number of molecular forms of lipids increases also at the expense of oxidized derivatives. The damage of the membranes due to chilling may be caused by lipid peroxidation initiated by different reactive oxygen species (ROS). The toxic product of the membrane lipid oxidation-malonic dialdehyde-accumulates at a rate that is higher in cold-sensitive plants. To alleviate these negative processes, the cellular membranes, including PM, elevate unsaturation of their lipids. The content of $\mathrm{C} 18: 1, \mathrm{C} 18: 2$, and $\mathrm{C} 18: 3$ rapidly rises, while 
that of $\mathrm{C} 16: 0$ and $\mathrm{C} 18: 0$ declines. The role of this process is especially important, since the mutants with disturbed encoding of desaturases exhibit no tolerance to cold stress. The cold-induced changes in lipid spectra can proceed in other cellular membranes as well. Simultaneously, the levels of PA and DGDG increase, while those of PC and MGDG decrease, which favors transformation of PC into PA afforded by phospholipase D. PA is a precursor in the galactolipid synthesis (occurring also in the plastid membranes) and an essential signal molecule fulfilling transduction of various signals. The transduction cascade, which has been initiated by PA, is then cross-integrated into $\mathrm{Ca}^{2+}$-signaling cascade and ABA-signaling [93]. Therefore, the membrane lipids play significant roles in adaptation to cold stress.

One more stressor type, deserving special attention, is somewhat opposite; this is extremely high temperature. The typical response of many plant species to this factor is a decrease in the degree of unsaturation. It is hypothesized that the rise in temperature is sensed by the calcium channels in the plasma membrane that are controlled by a rate of the membrane fluidity. As a result, the $\mathrm{Ca}^{2+}$ level rises, followed by its binding to calmodulin, and the activation of a family of transcription factors regulating the levels of various stress proteins, for example, heat-shock proteins [94]. Heating modulates a degree of the lipid unsaturation not only in the plasmalemma but also in the plastids and endoplasmic reticulum. These changes are also due to activity of fatty acid desaturases. The enhanced instability and longer exchange time of these enzymes take place under high temperatures. Changes in lipid unsaturation affect the activities of such signaling enzymes as phospholipases (including phospholipase $\mathrm{C}$ and D) and protein kinases. This elevates the concentrations of PA and/or inositol-3-phosphate. The signaling cascade is complicated due to a rise in ROS concentration (namely, accumulation of hydrogen peroxide by the activated NADPH oxidase within several minutes). Some other scenario is performed in the chloroplasts and mitochondria. Here, high temperature promotes peroxidation. The resultant ROS initiate retrograde signaling, which stabilizes PSII and, consequently, regulates the rate of photosynthesis. It is obvious that the mentioned heat-inducible processes considerably modify the composition of membranes, and this scientific area is still in progress.

Under natural conditions, superoptimal temperatures are very often combined with another stress factor-drought. Depletion of water leads to considerable morphological changes. One of the most prominent traits of drought-tolerant plants is the increase in unsaturation of their fatty acids [95]. Under this stressor, the tolerant plants accumulate polyunsaturated fatty acids C18:2 and C18:3. Comparison of watered and desiccated plants reveals significant difference in their lipid composition. Under water defi- ciency, the total content of lipids, as well as the content of their main classes, decline. Thus, the levels of PE, PS and PA decrease by 55\%. For some forms of MGDG, this index attains $70 \%$, although the decrease in DGDG is minor. As a result, the MGDG/DGDG ratio increases in more tolerant plants. The drought-tolerant pants contain more amounts of antioxidants inhibiting intense oxidation of fatty acids and production of oxylipins. Decrease in concentrations of ceramides and increase in steroids are also reported. Therefore, changes in the water regimen of plants significantly alter their lipidome.

Under phosphorous starvation, the substantial role of plastid GGL, when they substitute for phospholipids in cellular membranes, was discussed earlier [51, $54,60]$. In this respect, the discovery of a novel minor glyceroglycolipid, namely, GDG is worth attention, since this was done using a lipidomic approach [53]. Under phosphorous deficiency, the GPL content (especially that of PE, PI, and PG) decreases almost twofold in the Arabidopsis leaves. In the meantime, the GGL level significantly rises-two times for DGDG and GDG and 4.5 times for SQDG. In the rice seedlings, the GDG level increases five to seven times under these conditions. In the plastids, the GDG synthesis is coupled with the SQDG formation. The Arabidopsis mutants defective in biosynthesis of these GGL are more vulnerable than the wild type plants to the lack of phosphorus. GDG also accumulates in tomato and soybean plants deprived of phosphorus [96]. In addition to higher plants, GDG was found in algae.

Among different factors, modifying the lipidome of plant membranes, salinization also should be considered. Such modifications are known to play roles in plant adaptations to excessive concentrations of salts. High salinity $(250 \mathrm{mM} \mathrm{NaCl})$ considerably changes the profiles of GPL, GGL, SPL, and sterols in the roots of hydroponically cultured barley [97]. The plasma membrane is characterized by an increased content of the unsaturated C18:3 fatty acid in GPL; in addition, the plant response to salinization involves short- and medium-chain (C14-C18) fatty acids to a larger extent than the long-chain ones. The membranes of plastids are more sensitive to damage due to salinity than those of the plasma membrane. In plastid membranes, the lipid profiles manifest a general decrease in levels of all galactolipids, including GDG, increase in the MGDG/DGDG ratio, and accumulation of acetylsterylglycosides; this indicates partial degradation of chloroplast membranes. In the saltresistant cultivars, these damages are pronounced as weaker, with no signs of mitochondrial destruction. The salt stress is accompanied by DPG accumulation suggesting the important role of this lipid in sustaining the mitochondrial membrane stability [97].

Vital activity of the plants leads to numerous contacts with other organisms to establish quite different interactions from pathogenic to mutualistuic. Differ- 
ent groups of lipids are functionally involved in plantmicrobe interactions [98]. They are responsible for recognition of pathogens by a host-plant (ergosterol, for example) and signal transduction in the cells at the infection site (free fatty acids, oxylipins, glycerol-3phosphate, ceramides, and sphingoid bases). Besides, some lipids (azelaic acid) mediate transmission of an infective signal to the distal plant organs during development of systemic acquired resistance. Such lipids as lysophospholipids and $\omega$-hydroxy fatty acids participate in the processes associated with plant inoculation with mycorrhizal fungi. In addition, to build the arbuscular structures of the host plant cell and the arbuscular fungus, the intense synthesis of membrane lipids is necessary to create a large area for metabolite exchange between the partners during colonization.

In conclusion, we will consider the yet sparse examples of lipidome changes (especially in the membranes) in the course of growing processes of the plant cells. A very interesting case is the apical growth of the pollen tube. This structure arises upon germination of the pollen grain and grows within the stigma tissues. Simultaneously, its plasma membrane and tonoplast increase manifold in size [99]. The vesicular secretion becomes greatly important at this stage. The comparative lipidomic analysis of the pollen grain and the germinating one has revealed complex changes in lipid synthesis, in particular, de novo synthesis of several classes of lipids (structural and signaling). In some plant species, the GPL composition in the membranes of the growing pollen tube is similar to that of leaves. In the germinating pollen of Arabidopsis, PI and PA average nearly $50 \%$ of GPL. Here, extraplastid DGDG is actively synthesized. Sterols and SPL are of the most importance for pollen formation and germination. Mutants in their synthesis are often sterile. The $\mathrm{PM}$ of mature pollen is richer than that of vegetative tissues in SPL, especially glucosylceramides. The composition of sterols also differs in the membranes of pollen. Thus, the most abundant sterol in the vegetative tissues of plants is sitosterol $(60-75 \%)$, while 24-methylenecholesterol dominates $(45.5 \%)$ in the membranes of a male gametophyte; the sterol composition of growing pollen is more diverse [99]. Further investigations are needed for a comprehensive knowledge of events occurring in the lipidome of the germinating pollen and the surrounding tissues of the pistil.

The intensification of lipid synthesis accompanies another growth process-elongation growth, which takes place upon manifold rapid elongation of cotton fibers. The experimental evidence allows for suggesting that the biosynthesis of unsaturated fatty acids, PI, and phosphatidylinositolmonophosphates is activated at an early stage of fiber development [100]. Here, unsaturated PI and their phosphates prevail and may fulfill their functions in regulation and stimulation of elongation of cellular fibers.
The reported data demonstrate considerable differences in the changes of lipid profiles of different membranes. These changes may represent both rapid signals and adaptive rearrangements; they can also characterize the growth processes.

\section{CONCLUSIONS}

Summing up the modern data on proteome and lipidome of plant cellular membranes, the current intensification of these studies should be noted. This originates from diversity and permanent improvement of the novel methods of separation and detection based on chromatography linked with mass spectrometry. This method is incapable of exact quantitative analysis of the changes in protein or lipid content in a certain membrane. However, as a majority of "omic" approaches, it enables performing qualitative and semiquantitative analysis. The extension of bioinformatic resources, enabling estimation of changes occurring in total protein and lipid fractions, promotes the potential of these methods as well. The results of the work bring about deeper insight into dynamic modifications of protein and lipid profiles of normal and stress-impacted membranes. However, the available data are scarce and insufficient to characterize all the processes associated with growth and development.

The rapid increase in the number of publications on membrane proteome and lipidome shows the profound interest in this field of systemic biology. However, it must be emphasized that the biological membranes are not merely combinations of proteins and lipids composed in a proper ratio. At present, we are only beginning to perceive all the sophistication of mutual influence between different components, which determines both physicochemical properties and functional activity of biological membranes. That is why either proteins or lipids are active participants of various signaling systems. The evidence given in this review demonstrates that the integral membrane network of the plant cell not merely compartmentalizes the ongoing processes but also actively participates in them and regulates them. Nevertheless, massive investigations are undoubtedly needed to fill the gaps in our knowledge.

\section{ACKNOWLEDGMENTS}

We are grateful to Dr. E.L. Rudashevskaya for her valuable discussion.

\section{FUNDING}

This work was supported by the Russian Foundation for Basic Research, project no. 19-14-50413.

\section{COMPLIANCE WITH ETHICAL STANDARDS}

Conflict of interests. The authors declare that they have no conflicts of interest. 
Statement on the welfare of humans or animals. This article does not contain any studies involving humans or animals performed by any of the authors.

\section{OPEN ACCESS}

This article is licensed under a Creative Commons Attribution 4.0 International License, which permits use, sharing, adaptation, distribution and reproduction in any medium or format, as long as you give appropriate credit to the original author(s) and the source, provide a link to the Creative Commons license, and indicate if changes were made. The images or other third party material in this article are included in the article's Creative Commons license, unless indicated otherwise in a credit line to the material. If material is not included in the article's Creative Commons license and your intended use is not permitted by statutory regulation or exceeds the permitted use, you will need to obtain permission directly from the copyright holder. To view a copy of this license, visit http://creativecommons.org/licenses/by/4.0/.

\section{REFERENCES}

1. Singer, S.J. and Nicolson, G.L., The fluidmosaic model of the structure of cell membranes, Science, 1972, vol. 175 , p. 720.

https://doi.org/10.1126/science.175.4023.720

2. Nicolson, G.L., The fluid-mosaic model of membrane structure: still relevant to understanding the structure, function and dynamics of biological membranes after more than 40 years, Biochim. Biophys. Acta, Biomembr., 2014, vol. 1838, p. 1451. https://doi.org/10.1016/j.bbamem.2013.10.019

3. Wilkins, M.R., Pasquali, C., Appel, R.D., Ou, K., Golaz, O., Sanchez, J.-C., Yan, J.X., Gooley, A.A., Hughes, G., Humphery-Smith, I., Williams, K.L., and Hochstrasser, D.F., From proteins to proteomes: large scale protein identification by two-dimensional electrophoresis and amino acid analysis, Nat. Biotechnol., 1996, vol. 14, p. 61.

https://doi.org/10.1038/nbt0196-61

4. Newton, R.P., Brenton, A.G., Smith, C.J., and Dudley, E., Plant proteome analysis by mass spectrometry: principles, problems, pitfalls and recent developments, Phytochemistry, 2004, vol. 65, p. 1449.

https://doi.org/10.1016/j.phytochem.2004.04.015

5. Demidov, E.A., and Pel'tek, S.E., Proteomics, Vavilovskii Zh. Genet. Sel., 2014, vol. 18, p. 166.

6. Moshkovskii, S. and Ptashnik, O., 12 methods in pictures: proteomics. https://biomolecula.ru/articles/12metodov-v-kartinkakh-proteomika

7. Subba, P., Kotimoole, C.N., and Prasad, T.S.K., Plant proteome databases and bioinformatic tools: an expert review and comparative insights, OMICS, 2019, vol. 23, p. 190.

https://doi.org/10.1089/omi.2019.0024

8. Schwacke, R., Schneider, A., van der Graaff, E., Fischer, K., Catoni, E., Desimone, M., Frommer, W.B., Flügge, U.-I., and Kunze, R., ARAMEMNON, a novel database for Arabidopsis integral membrane pro- teins, Plant Physiol., 2003, vol. 131, p. 16. https://doi.org/10.1104/pp.011577

9. Tan, S., Tan, H.T., and Chung, M.C.M., Membrane proteins and membrane proteomics, Proteomics, 2008, vol. 8, p. 3924.

https://doi.org/10.1002/pmic.200800597

10. Kishimoto, K., Urade, R., Ogawa, T., and Moriyama, T., Nondestructive quantification of neutral lipids by thinlayer chromatography and laser-fluorescent scanning: suitable methods for "lipidome" analysis, Biochem. Biophys. Res. Commun., 2001, vol. 281, p. 657. https://doi.org/10.1006/bbrc.2001.4404

11. Akmurzina, V.A., Selishcheva, A.A., and Shvets, V.I., From lipid analysis to lipidomics, Vestn. Mosk. Inst. Tonkoi Khim. Tekhnol. im. M.V. Lomonosova, 2012, vol. 7, p. 3.

12. Namasivayam, E., Kowsalya, R., Padarthi, P.K., Manigandan, K., Jayaraj, R.L., Johnravindar, D., and Jagatheesh, K., Plant lipidomics: signaling and analytical strategies, in PlantOmics: The Omics of Plant Science, Barh D., Khan M.S., and Davies E., Eds., Berlin: Springer-Verlag, 2015, p. 331. https://doi.org/10.1007/978-81-322-2172-2_11

13. Shulaev, V. and Chapman, K.D., Plant lipidomics at the crossroads: from technology to biology driven science, Biochim. Biophys. Acta, Mol. Cell Biol. Lipids, 2017, vol. 1862, p. 786. https://doi.org/10.1016/j.bbalip.2017.02.011

14. Řezanka, T., Kolouchová, I., Gharwalová, L., Palyzová, A., and Sigler, K., Lipidomic analysis: from archaea to mammals, Lipids, 2018, vol. 53, p. 5. https://doi.org/10.1002/lipd.12001

15. Fahy, E., Subramaniam, S., Brown, H.A., Glass, C.K., Merrill, A.H., Jr., Murphy, R.C., Raetz, C.R.H., Russell, D.W., Seyama, Y., Shaw, W., Shimizu, T., Spener, F., van Meer, G., van Nieuwenhze, M.S., White, S.H., et al., A comprehensive classification system for lipids, J. Lipid Res., 2005, vol. 46, p. 839. https://doi.org/10.1194/jlr.E400004-JLR200

16. Brugiere, S., Kowalski, S., Ferro, M., Seigneurin-Berny, D., Miras, S., Salvi, D., Ravanel, S., d'Hérin, P., Garin, J., Bourguignon, J., Joyard, J., and Rolland, N., The hydrophobic proteome of mitochondrial membranes from Arabidopsis cell suspensions, Phytochemistry, 2004, vol. 65, p. 1693. https://doi.org/10.1016/j.phytochem.2004.03.028

17. Millar, A.H., Heazlewood, J.L., Kristensen, B.K., Braun, H.-P., and Møller, I.M., The plant mitochondrial proteome, Trends Plant Sci., 2005, vol. 10, p. 36. https://doi.org/10.1016/j.tplants.2004.12.002

18. Senkler, J., Senkler, M., Eubel, H., Hildebrandt, T., Lengwenus, C., Schertl, P., Schwarzlander, M., Wagner, S., Wittig I., and Braun, H.-P., The mitochondrial complexome of Arabidopsis thaliana, Plant J., 2017, vol. 89 , p. 1079.

https://doi.org/10.1111/tpj.13448

19. Peltier, J.B., Friso, G., Kalume, D.E., Roepstorff, P., Nilsson, F., Adamska, I., and van Wijk, K.J., Proteomics of the chloroplast: systematic identification and targeting analysis of lumenal and peripheral thylakoid proteins, Plant Cell, 2000, vol. 12, p. 319.

https://doi.org/10.1105/tpc.12.3.319 
20. Behrens, C., Blume, C., Senkler, M., Eubel, H., Peterhänsel, C., and Braun, H.-P., The 'protein complex proteome' of chloroplasts in Arabidopsis thaliana, J. Proteomics, 2012, vol. 91, p. 73. https://doi.org/10.1016/j.jprot.2013.07.001

21. Pendle, A.F., Clark, G.P., Boon, R., Lewandowska, D., Lam, Y.W., Andersen, J., Mann, M., Lamond, A.I., Brown, J.W.S., and Shaw, P.J., Proteomic analysis of the Arabidopsis nucleolus suggests novel nucleolar functions, Mol. Biol. Cell, 2005, vol. 16, p. 260. https://doi.org/10.1091/mbc.e04-09-0791

22. Giavalisco, P., Nordhoff, E., Kreitler, T., Kloppel, K.D., Lehrach, H., Klose, J., and Gobom, J., Proteome analysis of Arabidopsis thaliana by two-dimensional gel electrophoresis and matrix-assisted laser desorption/ionization-time of flight mass spectrometry, Proteomics, 2005, vol. 5, p. 1902. https://doi.org/10.1002/pmic.200401062

23. Tang, Y., Huang, A., and Gu, Y., Global profiling of plant nuclear membrane proteome in Arabidopsis, Nat. Plants, 2020, vol. 6, p. 838. https://doi.org/10.1038/s41477-020-0700-9

24. Goto, C., Hashizume, S., Fukao, Y., Hara-Nishimura, I., and Tamura, K., Comprehensive nuclear proteome of Arabidopsis obtained by sequential extraction, Nucleus, 2019, vol. 10, p. 81. https://doi.org/10.1080/19491034.2019.1603093

25. Collins, C.A., Leslie, M.E., Peck, S.C., and Heese, A., Simplified enrichment of plasma membrane proteins from Arabidopsis thaliana seedlings using differential centrifugation and Brij-58 treatment, Methods Mol. Biol., 2017, vol. 1564, p. 139. https://doi.org/10.1007/978-1-4939-6813-8_13

26. Larsson, C., Widell, S., and Kjellbom, P., Preparation of high-purity plasma membranes, Methods Enzymol., 1987 , vol. 148 , p. 558. https://doi.org/10.1016/0076-6879(87)48054-3

27. Ozolina, N.V., Nesterkina, I.S., Kolesnikova, E.V., Salyaev, R.K., Nurminsky, V.N., Rakevich, A.L., Martynovich, E.F., and Chernyshov, M.Yu., Tonoplast of Beta vulgaris L. contains detergent-resistant membrane microdomains, Planta, 2013, vol. 237, p. 859. https://doi.org/10.1007/s00425-012-1800-1

28. Trentmann, O. and Haferkamp, I., Current progress in tonoplast proteomics reveals insights into the function of the large central vacuole, Front. Plant Sci., 2013, vol. 4. 34. https://doi.org/10.3389/fpls.2013.00034

29. Chen, T., Kirpichnikova, A., Mikhaylova, Yu., and Shishova, M., Comparison of two systems of tonoplast purification from tobacco cells of suspension culture BY-2, Biol. Commun., 2020, vol. 65, p. 178. https://doi.org/10.21638/spbu03.2020.20

30. Ephritikhine, G., Ferro, M., and Rolland, N., Plant membrane proteomics, Plant Physiol. Biochem., 2004, vol. 42 , p. 943. https://doi.org/10.1016/j.plaphy.2004.11.004

31. Marmagne, A., Rouet, M.-A., Ferro, M., Rolland, N., Alcon, C., Joyard, J., Garin, J., Barbier-Brygoo, H., and Ephritikhine, G., Identification of new intrinsic proteins in Arabidopsis plasma membrane proteome,
Mol. Cell. Proteomics, 2004, vol. 3, p. 675. https://doi.org/10.1074/mcp.M400001-MCP200

32. Alexandersson, E., Saalbach, G., Larsson, C., and Kjellbom, P., Arabidopsis plasma membrane proteomics identifies components of transport, signal transduction and membrane trafficking, Plant Cell Physiol., 2004, vol. 45, p. 1543.

https://doi.org/10.1093/PCP/PCH209

33. Yadeta, K.A., Elmore, J.M., and Coaker, G., Advancements in the analysis of the Arabidopsis plasma membrane proteome, Front. Plant Sci., 2013, vol. 4, p. 86 https://doi.org/10.3389/fpls.2013.00086

34. Schulz, B., Functional classification of plant plasma membrane transporters, Plant Cell Monogr., 2011, vol. 19 , p. 131. https://doi.org/10.1007/978-3-642-13431-9_6

35. Testerink, C. and Munnik, T., Molecular, cellular, and physiological responses to phosphatidic acid formation in plants, J. Exp. Bot., 2011, vol. 62, p. 2349. https://doi.org/10.1093/jxb/err079

36. Elortza, F., Mohammed, S., Bunkenborg, J., Foster, L.J., Nühse, T.S., Brodbeck, U., Peck, S.C., and Jensen, O.N., Modification-specific proteomics of plasma membrane proteins: identification and characterization of glycosylphosphatidylinositol-anchored proteins released upon phospholipase D treatment, J. Proteome Res., 2006, vol. 5, p. 935. https://doi.org/10.1021/pr050419u

37. Cacas, J.-L., Furt, F., Le Guédard, M., Schmitter, J.-M., Buré, C., Gerbeau-Pissot, P., Moreau, P., Bessoule, J.-J., Simon-Plas, F., and Mongrand, S., Lipids of plant membrane rafts, Prog. Lipid Res., 2012, vol. 51, p. 272. https://doi.org/10.1016/j.plipres.2012.04.001

38. Tapken, W. and Murphy, A.S., Membrane nanodomains in plants: capturing form, function, and movement, J. Exp. Bot., 2015, vol. 66, p. 1573. https://doi.org/10.1093/jxb/erv054

39. Shimaoka, T., Ohnishi, M., Sazuka, T., Mitsuhashi, N., Hara-Nishimura, I., Shimazaki, K.-I., Maeshima, M., Yokota, A., Tomizawa, K.-I., and Mimura, T., Isolation of intact vacuoles and proteomic analysis of tonoplast from suspension-cultured cells of Arabidopsis thaliana, Plant Cell Physiol., 2004, vol. 45, p. 672. https://doi.org/10.1093/pcp/pch099

40. Jaquinod, M., Villiers, F., Kieffer-Jaquinod, S., Hugouvieux, V., Bruley, C., Garin, J., and Bourguignon, J., A proteomics dissection of Arabidopsis thaliana vacuoles isolated from cell culture, Mol. Cell. Proteomics, 2007, vol. 6, p. 394. https://doi.org/10.1074/mcp.M600250-MCP200

41. Dunkley, T.P.J., Hester, S., Shadforth, I.P., Runions, J., Weimar, T., Hanton, S.L., Griffin, J.L., Bessant, C., Brandizzi, F., Hawes, C., Watson, R.B., Dupree, P., and Lilley, K.S., Mapping the Arabidopsis organelle proteome, Proc. Natl. Acad. Sci. U.S.A., 2006, vol. 103, p. 6518. https://doi.org/10.1073/pnas.0506958103

42. Parsons, H.T., Christiansen, K., Knierim, B., Carroll, A., Ito, J., Batth, T.S., Smith-Moritz, A.M., Morrison, S., McInerney, P., Hadi, M.Z., Auer, M., Mukhopadhyay, A., Petzold, C.J., Scheller, H.V., Loqué, D., and Heazlewood, J.L., Isolation and proteomic characterization of the Arabidopsis Golgi de- 
fines functional and novel components involved in plant cell wall biosynthesis, Plant Physiol., 2012, vol. 159 , p. 12.

https://doi.org/10.1104/pp.111.193151

43. Wang, X. and Komatsu, S., Plant subcellular proteomics: application for exploring optimal cell function in soybean, J. Proteomics, 2016, vol. 143, p. 45. https://doi.org/10.1016/j.jprot.2016.01.011

44. Takahashi, D., Kawamura, Y., Yamashita, T., and Uemura, M., Detergent-resistant plasma membrane proteome in oat and rye: similarities and dissimilarities between two monocotyledonous plants, J. Proteome Res., 2012, vol. 11, p. 1654.

https://doi.org/10.1021/pr200849v

45. Krishnamurthy, P., Tana, X.F., Lima, T.K., Lima, T.-M., Kumar, P.P., Loh, C.-S., and Lin, Q., Data in support of the proteomic analysis of plasma membrane and tonoplast from the leaves of mangrove plant Avicennia officinalis, Data Brief, 2015, vol. 5, p. 646. https://doi.org/10.1016/j.dib.2015.10.016

46. Datta, R., Kumar, D., and Chattopadhyay, S., Membrane proteome profiling of Mentha arvensis leaves in response to Alternaria alternate infection identifies crucial candidates for defense response, Plant Signaling Behav., 2018, vol. 13, p. e1178423. https://doi.org/10.1080/15592324.2016.1178423

47. Nilsson, R., Bernfur, K., Gustavsson, N., Bygdell, J., Wingsle, G., and Larsson, C., Proteomics of plasma membranes from poplar trees reveals tissue distribution of transporters, receptors, and proteins in cell wall formation, Mol. Cell. Proteomics, 2010, vol. 9, p. 368. https://doi.org/10.1074/mcp.M900289-MCP200

48. Iwasaki, Y., Itoh, T., Hagi, Y., Matsuta, S., Nishiyama, A., Chaya, G., Kobayashi, Y., Miura, K., and Komatsu, S., Proteomics analysis of plasma membrane fractions of the root, leaf, and flower of rice, Int. J. Mol. Sci., 2020, vol. 21, p. 6988. https://doi.org/10.3390/ijms21196988

49. Furt, F., Simon-Plas, F., and Mongrand, S., Lipids of the plant plasma membrane, Plant Cell Monogr., 2011, vol. 19 , p. 3 . https://doi.org/10.1007/978-3-642-13431-9_1

50. Paradies, G., Paradies, V., De Benedictis, V., Ruggiero, F.M., and Petrosillo, G., Functional role of cardiolipin in mitochondrial bioenergetics, Biochim. Biophys. Acta, Bioenerg., 2014, vol. 1837, p. 408. https://doi.org/10.1016/j.bbabio.2013.10.006

51. Cassim, A.M., Gouguet, P., Gronnier, J., Laurent, N., Germain, V., Grison, M., Boutté, Y., Gerbeau-Pissot, P., Simon-Plas, F., and Mongrand, S., Plant lipids: key players of plasma membrane organization and function, Prog. Lipid Res., 2019, vol. 73, p. 1. https://doi.org/10.1016/j.plipres.2018.11.002

52. Boudière, L., Michaud, M., Petroutsos, D., Rébeillé, F., Falconet, D., Bastien, O., Roy, S., Finazzi, G., Rolland, N., Jouhet, J., Block, M.A., and Maréchal, E., Glycerolipids in photosynthesis: Composition, synthesis and trafficking, Biochim. Biophys. Acta, Bioenerg., 2014, vol. 1837 , p. 470.

http://doi.doi.org/10.1016/j.bbabio.2013.09.007

53. Okazaki, Y., Otsuki, H., Narisawa, T., Kobayashi, M., Sawai, S., Kamide, Y., Kusano, M., Aoki, T., Hirai, M.Y., and Saito, K., A new class of plant lipid is essential for protection against phosphorus depletion, Nat. Commun., 2013, vol. 4, p. 1510.

https://doi.org/10.1038/ncomms2512

54. Li-Beisson, Y., Shorrosh, B., Beisson, F., Andersson, M.X., Arondel, V., Bates, P.D., Baud, S., Bird, D., DeBono, A., Durrett, T.P., Franke, R.B., Graham, I.A., Katayama, K., Kelly, A.A., Larson, T., et al., Acyl-lipid metabolism, Arabidopsis Book, 2013, vol. 11, p. e0161. https://doi.org/10.1199/tab.0161

55. Merrill, A.H., Jr. and Sullards, M.C., Opinion article on lipidomics: inherent challenges of lipidomic analysis of sphingolipids, Biochim. Biophys. Acta, Mol. Cell Biol. Lipids, 2017, vol. 1862, p. 774. https://doi.org/10.1016/j.bbalip.2017.01.009

56. Pata, M.O., Hannun, Y.A., and Ng, C.K.-Y., Plant sphingolipids: decoding the enigma of the Sphinx, New Phytol., 2010, vol. 185, p. 611. https://doi.org/10.1111/j.1469-8137.2009.03123.x

57. Valitova, J.N., Sulkarnayeva, A.G., and Minibayeva, F.V., Plant sterols: diversity, biosynthesis, and physiological functions, Biochemistry (Moscow), 2016, vol. 81, p. 819 . https://doi.org/10.1134/S0006297916080046

58. Moreau, P., Bessoule, J.J., Mongrand, S., Testet, E., Vincent, P., and Cassagne, C., Lipid trafficking in plant cells, Prog. Lipid Res., 1998, vol. 37, p. 371. https://doi.org/10.1016/S0163-7827(98)00016-2

59. Garab, G., Ughy, B., and Goss, R., Role of MGDG and non-bilayer lipid phases in the structure and dynamics of chloroplast thylakoid membranes, Subcell. Biochem., 2016. 86, p. 127. https://doi.org/10.1007/978-3-319-25979-6_6

60. Tjellström, H., Hellgren, L.I., Wieslander, Å., and Sandeliuset, A.S., Lipid asymmetry in plant plasma membranes: phosphate deficiency-induced phospholipid replacement is restricted to the cytosolic leaflet, FASEB J., 2010, vol. 24, p. 1128. https://doi.org/10.1096/fj.09-139410

61. Horvath, S.E. and Daum, G., Lipids of mitochondria, Prog. Lipid Res., 2013, vol. 52, p. 590. https://doi.org/10.1016/j.plipres.2013.07.002

62. Zhang, C., Hicks, G.R., and Raikhel, N.V., Molecular composition of plant vacuoles: Important but less understood regulations and roles of tonoplast lipids, Plants, 2015, vol. 4, p. 320. https://doi.org/10.3390/plants4020320

63. Michaud, M., Prinz, W.A. and Jouhet, J., Glycerolipid synthesis and lipid trafficking in plant mitochondria, FEBS J., 2017, vol. 284, p. 376.

https://doi.org/10.1111/febs.13812

64. Fouillen, L., Maneta-Peyret, L., and Moreau, P., ER membrane lipid composition and metabolism: lipidomic analysis, Methods Mol. Biol., 2018, vol. 1691, p. 125. https://doi.org/10.1007/978-1-4939-7389-7_10

65. Markham, J.E., Lynch, D.V., Napier, J.A., Dunn, T.M., and Cahoon, E.B., Plant sphingolipids: function follows form, Curr. Opin. Plant Biol., 2013, vol. 16, p. 350. https://doi.org/10.1016/j.pbi.2013.02.009

66. Nesterkina, I.S., Ozolina, N.V., Baduev, B.K., Fedorova, G.A., Nurminskii, V.N., Spiridonova, E.V., and 
Salyaev, R.K., Rafts of vacuolar membranes of Beta vulgaris L. contain V-H $\mathrm{H}^{+}$-ATP-ase, Biol. Membr., 2016, vol. 33, p. 450.

https://doi.org/10.7868/S0233475516060098

67. König, S., Mosblech, A., and Heilmann, I., Stress-inducible and constitutive phosphoinositide pools have distinctive fatty acid patterns in Arabidopsis thaliana, FASEB J., 2007, vol. 21, p. 1958.

https://doi.org/10.1096/FJ.06-7887COM

68. Cacas, J.-L., Buré, C., Grosjean, K., Gerbeau-Pissot, P., Lherminier, J., Rombouts, Y., Maes, E., Bossard, C., Gronnier, J., Furt, F., Fouillen, L., Germain, V., Bayer, E., Cluzet, S., Robert, F., et al., Revisiting plant plasma membrane lipids in tobacco: a focus on sphingolipids, Plant Physiol., 2016, vol. 170, p. 367. https://doi.org/10.1104/pp.15.00564

69. Nyholm, T.K.M., Lipid-protein interplay and lateral organization in biomembranes, Chem. Phys. Lipids, 2015, vol. 189, p. 48. https://doi.org/10.1016/j.chemphyslip.2015.05.008

70. Grison, M.S., Brocard, L., Fouillen, L., Nicolas, W., Wewer, V., Dörmann, P., Nacir, H., Benitez-Alfonso, Y., Claverol, S., Germain, V., Boutté, Y., Mongrand, S., and Bayer, E.M., Specific membrane lipid composition is important for plasmodesmata function in Arabidopsis, Plant Cell, 2015, vol. 27, p. 1228. https://doi.org/10.1105/tpc.114.135731

71. Gronnier, J., Crowet, J.-M., Habenstein, B., Nasir, M.N., Bayle, V., Hosy, E., Platre, M.P., Gouguet, P., Raffaele, S., Martinez, D., Grelard, A., Loquet, A., Simon-Plas, F., Gerbeau-Pissot, P., Der, C., et al., Structural basis for plant plasma membrane protein dynamics and organization into functional nanodomains, eLife, 2017, vol. 6, p. e26404. https://doi.org/10.7554/eLife.26404

72. van Meer, G., Voelker, D.R., and Feigenson, G.W., Membrane lipids: where they are and how they behave, Nat. Rev. Mol. Cell. Biol., 2008, vol. 9, p. 112. https://doi.org/10.1038/nrm2330

73. Nohzadeh, M.S., Habibi, R.M., Heidari, M., and Salekdeh, G.H., Proteomics reveals new salt responsive proteins associated with rice plasma membrane, Biosci., Biotechnol. Biochem., 2007, vol. 71, p. 2144. https://doi.org/10.1271/bbb.70027

74. Cheng, Y., Qi, Y., Zhu, Q., Chen, X., Wang, N., Zhao, X., Chen, H., Cui, X., Xu, L., and Zhang, W., New changes in the plasma-membrane-associated proteome of rice roots under salt stress, Proteomics, 2009, vol. 9, p. 3100. https://doi.org/10.1002/pmic. 200800340

75. Witzel, K., Matros, A., Møller, A.L.B., Ramireddy, E., Finnie, C., Peukert, M., Rutten, T., Herzog, A., Kunze, G., Melzer, M., Kaspar-Schoenefeld, S., Schmülling, T., Svensson, B., and Mock, H.-P., Plasma membrane proteome analysis identifies a role of barley membrane steroid binding protein in root architecture response to salinity, Plant Cell Environ., 2018, vol. 41, p. 1311. https://doi.org/10.1111/pce.13154

76. Takahashi, D., Li, B., Nakayama, T., Kawamura, Y., and Uemura, M., Plant plasma membrane proteomics for improving cold tolerance, Front. Plant Sci., 2013, vol. 4 , p. 90.

https://doi.org/10.3389/fpls.2013.00090

77. Miki, Y., Takahashi, D., Kawamura, Y., and Uemura, M., Temporal proteomics of Arabidopsis plasma membrane during cold- and deacclimation, J. Proteomics, 2019, vol. 197 , p. 71

https://doi.org/10.1016/j.jprot.2018.11.008

78. Komatsu, S. and Hashiguchi, A., Subcellular proteomics: application to elucidation of flooding-response mechanisms in soybean, Proteomes, 2018, vol. 6: 13. https://doi.org/10.3390/proteomes6010013

79. Elmore, J.M., Liu, J., Smith, B., Phinney, B., and Coaker, G., Quantitative proteomics reveals dynamic changes in the plasma membrane during Arabidopsis immune signaling, Mol. Cell. Proteomics, 2012, vol. 11, art. ID M111.014555. https://doi.org/10.1074/mcp.M111.014555

80. Aloui, A., Recorbet, G., Lemaître-Guillier, C., Mounier, A., Balliau, T., Zivy, M., Wipf, D., and DumasGaudot, E., The plasma membrane proteome of $\mathrm{Med}$ icago truncatula roots as modified by arbuscular mycorrhizal symbiosis, Mycorrhiza, 2018, vol. 28, p. 1. https://doi.org/10.1007/s00572-017-0789-5

81. Wienkoop, S. and Saalbach, G., Proteome analysis. Novel proteins identified at the peribacteroid membrane from Lotus japonicus root nodules, Plant Physiol., 2003, vol. 131, p. 1080. https://doi.org/10.1104/pp.102.015362

82. Kutschera, U., Deng, Z., Oses-Prieto, J.A., Burlingame, A.L., and Wang, Z.-Y., Cessation of coleoptile elongation and loss of auxin sensitivity in developing rye seedlings: a quantitative proteomic analysis, Plant Signaling Behav., 2010, vol. 5, p. 509.

https://doi.org/10.4161/psb.11210

83. Zhu, J., Chen, S., Alvarez, S., Asirvatham, V.S., Schachtman, D.P., Wu, Y., and Sharp, R.E., Cell wall proteome in the maize primary root elongation zone. I. Extraction and identification of water-soluble and lightly ionically bound proteins, Plant Physiol., 2006, vol. 140 , p. 311. https://doi.org/10.1104/pp.105.070219

84. Zhu, J., Alvarez, S., Marsh, E.L., LeNoble, M.E., Cho, I.-J., Sivaguru, M., Chen, S., Nguyen, H.T., Wu, Y., Schachtman, D.P., and Sharp, R.E., Cell wall proteome in the maize primary root elongation zone. II. Region-specific changes in water soluble and lightly ionically bound proteins under water deficit, Plant Physiol., 2007, vol. 145, p. 1533.

https://doi.org/10.1104/pp.107.107250

85. Zhang, Z., Voothuluru, P., Yamaguchi, M., Sharp, R.E., and Peck, S.C., Developmental distribution of the plasma membrane-enriched proteome in the maize primary root growth zone, Front. Plant Sci., 2013, vol. 4 , p. 33. https://doi.org/10.3389/fpls.2013.00033

86. Li, B., Takahashi, D., Kawamura, Y., and Uemura, M., Plasma membrane proteome analyses of Arabidopsis thaliana suspension-cultured cells during cold or ABA treatment: relationship with freezing tolerance and growth phase, J. Proteomics, 2020, vol. 211, p. 103528. https://doi.org/10.1016/j.jprot.2019.103528

87. Pertl, H., Schulze, W.X., and Obermeyer, G., The pollen organelle membrane proteome reveals highly 
spatial-temporal dynamics during germination and tube growth of lily pollen, J. Proteome Res., 2009, vol. 8, p. 5142.

https://doi.org/10.1021/pr900503f

88. Yang, N. and Wang, T., Comparative proteomic analysis reveals a dynamic pollen plasma membrane protein map and the membrane landscape of receptor-like kinases and transporters important for pollen tube growth and interaction with pistils in rice, BMC Plant Biol., 2017, vol. 17, p. 2. https://doi.org/10.1186/s12870-016-0961-7

89. Pontiggia, D., Spinelli, F., Fabbri, C., Licursi, V., Negri, R., De Lorenzo, G., and Mattei, B., Changes in the microsomal proteome of tomato fruit during ripening, Sci. Rep., 2019, vol. 9, p. 14350.

https://doi.org/10.1038/s41598-019-50575-5

90. Zhang, J., Ma, H., Feng, J., Zeng, L., Wang, Z., and Chen, S., Grape berry plasma membrane proteome analysis and its differential expression during ripening, J. Exp. Bot., 2008, vol. 59, p. 2979. https://doi.org/10.1093/jxb/ern156

91. Liu, R., Wang, Y., Qin, G., and Tian, S., iTRAQ-based quantitative proteomic analysis reveals the role of the tonoplast in fruit senescence, J. Proteomics, 2016, vol. 146, p. 80.

https://doi.org/10.1016/j.jprot.2016.06.031

92. Nakamura, Y., Membrane lipid oscillation: an emerging system of molecular dynamics in the plant membrane, Plant Cell Physiol., 2018, vol. 59, p. 441. https://doi.org/10.1093/pcp/pcy023

93. Zhang, H., Dong, J., Zhao, X., Zhang, Y., Ren, J., Xing, L., Jiang, C., Wang, X., Wang, J., Zhao, S., and $\mathrm{Yu}, \mathrm{H}$., Research progress in membrane lipid metabolism and molecular mechanism in peanut cold tolerance, Front. Plant Sci., 2019, vol. 10, p. 838. https://doi.org/10.3389/fpls.2019.00838

94. Niu, Y. and Xiang, Y., An overview of biomembrane functions in plant responses to high-temperature stress, Front. Plant Sci., 2018, vol. 9, p. 915. https://doi.org/10.3389/fpls.2018.00915

95. Moradi, P., Mahdavi, A., Khoshkam, M., and Iriti, M., Lipidomics unravels the role of leaf lipids in thyme plant response to drought stress, Int. J. Mol. Sci., 2017, vol. 18, p. 2067. https://doi.org/10.3390/ijms 18102067

96. Okazaki, Y., Nishizawa, T., Takano, K., Ohnishi, M., Mimura, T., and Saito, K., Induced accumulation of glucuronosyldiacylglycerol in tomato and soybean under phosphorus deprivation, Physiol. Plant., 2015, vol. 155 , p. 33.

https://doi.org/10.1111/ppl.12334

97. Yu, D., Boughton, B.A., Hill, C.B., Feussner, I., Roessner, U., and Rupasinghe, T.W.T., Insights into oxidized lipid modification in barley roots as an adaptation mechanism to salinity stress, Front. Plant Sci., 2020, vol. 11, p. 1 .

https://doi.org/10.3389/fpls.2020.00001

98. Siebers, M., Brands, M., Wewer, V., Duan, Y., Hölzl, G., and Dörmann, P., Lipids in plant-microbe interactions, Biochim. Biophys. Acta, Mol. Cell Biol. Lipids, 2016, vol. 1861, p. 1379.

https://doi.org/10.1016/j.bbalip.2016.02.021

99. Ischebeck, T., Lipids in pollen-they are different, Biochim. Biophys. Acta, Mol. Cell Biol. Lipids, 2016, vol. 1861 , p. 1315.

https://doi.org/10.1016/j.bbalip.2016.03.023

100. Liu, G.-J., Xiao, G.-H., Liu, N.-J., Liu, D., Chen, P.-S., Qin, Y.-M., and Zhu, Y.-X., Targeted lipidomics studies reveal that linolenic acid promotes cotton fiber elongation by activating phosphatidylinositol and phosphatidylinositol monophosphate biosynthesis, Mol. Plant., 2015, vol. 8, p. 911.

https://doi.org/10.1016/j.molp.2015.02.010

Translated by A. Aver'yanov 